\title{
CD36 mRNA and Protein Expression Levels Are Significantly Increased in the Heart and Testis of apoE Deficient Mice in Comparison to Wild Type (C57BL/6)
}

\author{
Kazem Zibara,* Eric Malaud, and John L. McGregor \\ (Equal participation of $K Z$ and $E M$ )
}

Institut National de la Santé et de la Recherche Médicale (INSERM) U331, Faculté de Médecine RTH Laënnec, Lyon, France

\begin{abstract}
CD36, an 88kd-adhesion molecule, plays a major role as a scavenging receptor implicated in cellular lipid metabolism. Secretory mammary epithelium, microvasculature endothelium, adipocytes, smooth muscle cells, and platelets express CD36. In addition, CD36 expression is significantly enhanced in macrophages differentiating into foam cells. The effect of pathological levels of cholesterol, as observed in apoE ${ }^{-/-}$, on vascular CD36 expression is, at this stage, not known. In this study, a quantitative analysis of CD36 transcription and protein expression levels, present in tissues of male C57BL/6 and apolipoprotein-E (apoE) deficient mice was carried out by Northern and Western blots. Four-week-old animals were fed a chow diet over different periods of time $(0,6$, 16, or 20 weeks). Immunohistochemistry was used to localize CD36 protein expression in the heart and testis. Results indicate that CD36 transcription is increased in hearts of apoE deficient animals (100\% higher at 6 weeks, and 30\% higher at 16 and 20 weeks) in comparison to wild type. This was confirmed at the protein level, which showed an increase of at least $100 \%$ at 6 weeks, and between $40 \%$ to $50 \%$ increase at 16 and 20 weeks of apoE $\mathrm{E}^{-/-}$mice compared to controls. In addition, CD36 transcription levels were significantly increased in testis of apoE animals (at least $100 \%$ at 6,16 , and 20 weeks) compared to C57BL/6 wild type. Such an increase was also confirmed at the protein level ( $65 \%$ increase at 16 weeks in apoE mice compared to control). Finally, localization of CD36 protein expression by immunohistochemistry showed that it was expressed in the capillaries of heart and testis endothelial cells and also at the head of spermatozoid during spermatogenesis. These results indicate that high circulating cholesterol levels, in apoE deficient mice, significantly enhance the expression of CD36 in the heart and testis. Such enhanced CD36 expression might lead to organ remodeling and/or dysfunction.
\end{abstract}

\section{INTRODUCTION}

CD36, an 88 kd highly glycosylated glycoprotein, has a number of putative ligands including thrombospondin, oxidized low density lipoprotein (OxLDL), collagen and longchain fatty acids $[1,2,3,4]$. A wide variety of cells and tissues, such as platelets, monocytes/macrophages, microvasculature endothelial cell, erythrocyte precursors, spleen tissue, smooth muscles, mammary epithelium, and adipocytes express CD36 [3, 4, 5, 6, 7, 8]. Expression of CD36 in endothelial cells is heterogeneous and is tissue-specific. Indeed, endothelial cells lining large arterial vessels or brain capillaries do not stain for CD36 $[9,10]$. In contrast, CD36 is highly expressed in endothelial cells of adipose tissue, differentiated mammary epithelial tissue, and cardiac and skeletal muscles $[6,9,11]$. CD36, also known as fatty acid translocase (FAT) in rat adipocytes or PASIV in bovine mammary, is a member of class B scavenger receptors $[4,12]$. CD36 is involved in the endocytosis of OxLDL and in the phagocytosis, in tandem with $\alpha v \beta 3$, of apoptotic neutrophils [2, 13]. In addition, CD36 is also implicated in the cytoadherence of erythrocytes infected by Plasmodium falciparum [14].
OxLDL scavenging receptors play a crucial role in the initiation and perpetuation of vascular lesions $[15,16]$. Indeed, capacity of CD36 to bind and internalize OxLDL is thought to modulate the differentiation of macrophages into foam cells $[2,17,18,19]$. A region on CD36, encompassing amino acids 155-183, was identified as the OxLDL binding site [20]. Nozaki et al showed in monocytes-derived macrophages, from subjects presenting a deficit in CD36 expression, a $40 \%$ reduction in their capacity to accumulate OxLDL [21]. Moreover, a mouse deficiency of CD36 in an apoE knockout was shown to greatly reduce the size of vascular lesions [22]. However, such CD36-deficient mice show a high plasmatic level of cholesterol, nonesterified free acids and triacylglycerol [23]. The critical role of CD36 in monocytes differentiation into macrophages, as shown by Tontonoz et al and Nagy et al, is linked to its capacity in OxLDL uptake $[24,25]$. OxLDL, via CD36, induces the activation of peroxisome proliferator-activated receptor $\gamma(\operatorname{PPAR} \gamma)$ and the subsequent lipid accumulation in macrophages [24, 25].

Very little is known on how increased levels of triacylglycerol and total cholesterol, in the circulation of apoE deficient mice, might affect CD36 expression in the vasculature 
of different organs. This study has investigated CD36 expression in different organs and reports, for the first time, significant increased levels of CD36 in the heart and testis of apoE deficient but not wild-type (C57BL/6) mice.

\section{METHODS}

\section{Animal handling}

Surgical procedures and animal care are strictly conformed to the Guidelines of the National Institute of Health and Medical Research (Decree No. 87-848 October 19, 1987). All animals used in this study were ether anesthetized before organ sampling.

\section{Mice}

The apoE $E^{\mathrm{mlUnc}}$ line was obtained from Dr N. Maeda (Chapel Hill, North Carolina University, USA). Control C57BL/6JIco and apoE deficient mice (C57BL/6JIco background) were backcrossed, bred, and housed, under specific and opportunistic pathogen-free conditions, by Transgenic Alliance (Iffa Credo S.A., Lyon, France). Both control $(n=$ $48)$ and apoE deficient mice $(n=48)$ were weaned at 3 weeks of age and maintained on chow diet for 1 week ("Souriffarat" breeding diet, standard formulation, and pellets, irradiated at $25 \mathrm{kGy}$, from Extralabo, France). Following that stage, mice had access to a chow (4\% fat, 0\% cholesterol) diet and received water and food ad libitum during the 0-, 6-, 16-, and 20 -week schedules. Control and apoE deficient mice, at the end of each feeding period, were anesthetized by ether inhalation. Subsequently the thoracic cavity was opened, the heart and other organs were removed and sampled. Fragments of tissues were snap frozen in liquid nitrogen, and stored at $-80^{\circ} \mathrm{C}$ for later use for molecular and cellular biology techniques. Tissue fragments were also rapidly embedded in optimal cutting temperature (OCT) compound, (Miles Laboratories Inc., Elkhart, IN, USA) and frozen in liquid nitrogen for later use for immunohistochemistry.

\section{Cholesterol level analysis}

It was carried out in the blood collected from the retroorbital sinus of anesthetized animals at the end of each observation period before sacrifice. Total cholesterol was determined using commercially available assay kits (Boehringer Mannheim, France) and expressed in mmol/L. apoE ${ }^{-/-}$chow fed mice showed, at 0 weeks of diet, higher plasma cholesterol levels $(9.594 \pm 0.624 \mathrm{mmol} / \mathrm{L})$, prior to diet feeding, in comparison to wild type C57BL/6 animals $(2.312 \pm 0.259)$. These significant differences, between both strains, were maintained at all phases of the experiment. The following values were obtained for chow fed $\mathrm{apoE}^{-/-}$and $\mathrm{C} 57 \mathrm{BL} / 6$ mice at $0,6,16$, and 20 weeks, respectively, [(9.594 \pm 0.624 , $2.312 \pm 0.259) ;(18.27 \pm 3.209,2.966 \pm 0.401) ;(23.501 \pm 3.801$, $2.532 \pm 0.176) ;(19.866 \pm 2.32,2.635 \pm 0.538 \mathrm{mmol} / \mathrm{L})]$.

\section{Total RNA isolation}

Tissue samples from C57BL/6 and apoE ${ }^{-/-}$mice $(n=96)$, isolated at different periods of time $(0,6,16,20$ weeks $)$, were snap frozen in liquid nitrogen and stored at $-80^{\circ} \mathrm{C}$. Total RNA was extracted from samples $(n=6)$ at each indicated time. Briefly, frozen tissues were ground in a mortar in liquid nitrogen. The frozen powdered sample was immediately mixed with TRIzol (Gibco BRL, Life Technologies) and homogenized with a Polytron. Total RNA was extracted using the TRIzol method adapted from the Chomczynski and Sacchi procedure [26].

\section{CD36 probe synthesis and labeling}

The 693bp CD36 probe was prepared by RTPCR. The following primers (CD36-275U19: GAGGAGAATGGGCTGTGAT and CD36-948L21: GGACTCAATTATGGCAACTTT) were used for PCR amplification. RT-PCR, labeling and purification were done according to standard techniques.

\section{Northern blot}

Total RNA $(20 \mu \mathrm{g})$ was denatured, separated by electrophoresis on a formaldehyde-MOPS-agarose gel and then transferred to a nylon membrane (Hybond N+, Amersham, UK). After capillary blotting, performed overnight, the membrane was baked for 2 hours at $80^{\circ} \mathrm{C}$. Prehybridization and hybridization were done according to standard protocols [27]. Blots were exposed against a phosphorimager screen (Molecular Dynamics) for 24 hours. Scanning was done under a $100 \mu$ scale and the ImageQuant software was then used for quantification. Variations in RNA loading was assessed using 28S that allowed normalizing of CD36 values. All quantification values were corrected for background levels using the local median method of the ImageQuant software. The initial scan image (gel format) was transferred into a Tiff file to allow its presentation in the figures of the manuscript.

\section{Protein preparation and Western blot}

Hearts and testis maintained in liquid nitrogen were pound in a mortar, then homogenized at $0^{\circ} \mathrm{C}$ (two 10 -second burst) in tris-buffered saline containing $1 \%$ aprotinin, $2 \mathrm{mmol} / \mathrm{L} \varepsilon$-aminocaproic acid and $0.5 \mathrm{mmol} / \mathrm{L}$ phenylmethylsulfonyl fluoride. The homogenate was centrifuged at $1000 \mathrm{~g}$ for 5 minutes to remove the unhomogenized fragments. The supernatant was then centrifuged at $100.000 \mathrm{~g}$ for 1 hour to obtain microsomal (membrane proteins) and supernatant (cytoplasmic proteins) fractions. The pellets of microsomal fractions were solubilized in SDS 1\%. Microsomes were diluted in Laemmli SDS-PAGE lysis buffer and their proteins were separated on $10 \%$ acrylamide SDS-PAGE gels. The proteins were transferred to a nitrocellulose membrane and blocked for 4 hours with 10\% nonfat milk and $0.05 \%$ Tween 20 in tris-buffered saline $\mathrm{pH} 7.5$. The CD36 band on Western blots was identified through the use of a guinea pig anti-mouse CD36 (dilution 1/1000), followed by a horseradish peroxidase conjugated goat anti-guinea pig antibody (DAKO), and ECL reagents used according to the manufacture's instructions (Amersham) [28]. ECL films were scanned with Sharp JX-330 scanner (Amersham) and CD36 
bands were quantified with Total Lab Software (Amersham). In parallel, SDS-PAGE gels, containing identical sample volumes to those used for the Western blot were Coomassie stained. Electrophoretic bands of 50 and $200 \mathrm{kd}$ (for heart samples) and $50 \mathrm{kd}$ (for testis samples) were scanned and used as a quantitative control to check for sample loading and CD36 normalization.

\section{Immunohistochemistry}

Serial sections $(6 \mu \mathrm{m})$ were generated on a cryostat, mounted on gelatin coated slides. Immediately before staining, frozen sections were air dried for 1 hour at room temperature (RT), fixed in 100\% ice-cold acetone for 5 minutes, and again air dried for 15 minutes. Sections, originating from apoE and C57BL6 animals were stained as described below. Antibodies used were a guinea pig antiserum against murine CD36 (dilution 1/500) and a non-immune guinea pig serum (dilution 1/500) used as negative control [28]. Following acetone fixation and blocking, CD36 was visualized after incubation with a rabbit anti-guinea pig immunoglobulin (peroxidase labeled polymer conjugated to goat anti-rabbit immunoglobulins and 3-amino-9-ethylcarbazole) (EnVision + System Peroxidase, Dako, France). A non-immune guinea pig serum was used at the place of the primary antibodies as a negative control. Immunostained sections were counterstained with hematoxylin.

\section{RESULTS}

CD36 mRNA and protein expression were assayed on organs of $\mathrm{apoE}^{-/-}$and $\mathrm{C} 57 \mathrm{BL} / 6$ mice fed 0- to 20-week chow diet, through the use of Northern, Western blots and immunohistochemistry techniques. Cholesterol levels for apoE deficient animals were significantly higher than the wild type at all stages of the protocol $(0,6,16$, and 20 weeks, see Methods section).

\section{mRNA levels of CD36 in different tissues}

Northern blots, in C57BL/6 wild-type mice, showed the presence of CD36 RNA transcripts in the heart, lung, kidney, skeletal muscles, and to a lesser extent in the spleen (Figure 1a).

The gradient of CD36 gene transcript expression was at its lowest value in the testis and the highest in the heart. In contrast, apoE deficient mice showed higher CD36 mRNA levels in the heart and testis (200\% increase), at 6 weeks of chow diet (Figure 1b). It is of interest to note that kidney CD36 mRNA levels were also increased. These results suggest that three of the tested organs (heart, testis, and kidney) are affected by high cholesterol and triacylglycerol levels. In this study, we have focused on the heart and testis tissues since they showed the highest differences in mRNA levels between knockout and wild-type animals.

\section{mRNA and protein levels of CD36 in the heart}

The hearts of apoE deficient mice presented an increase in CD36 steady state RNAs, in comparison to wild type,

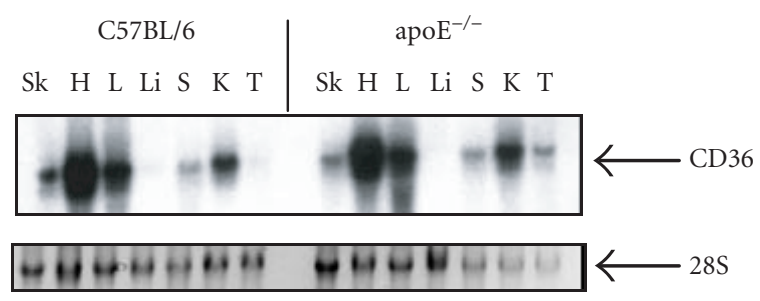

(a) Representative northern blot showing transcription levels of CD36 in skeletal muscles (Sk), heart (H), lung (L), liver (Li), spleen (S), kidney $(\mathrm{K})$ and testis $(\mathrm{T})$ of apoE deficient mice, in comparison to wild type $(\mathrm{C} 57 \mathrm{BL} / 6)$. Blots contained $20 \mu \mathrm{g}$ of total RNA. A control for loading and for quantification (28S) was also used.

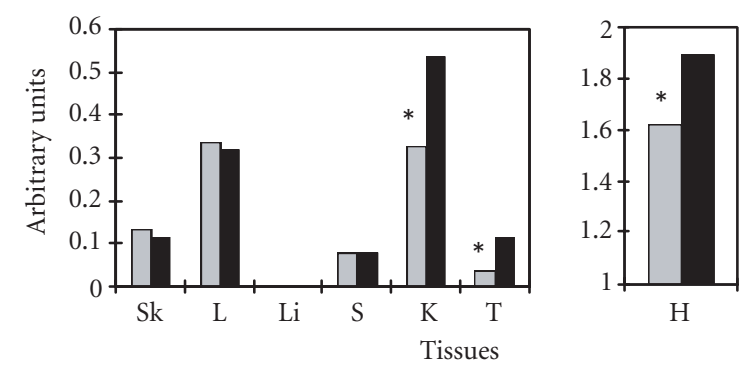

(b) Quantification of CD36 signals reported to control 28S levels. $\mathrm{C} 57 \mathrm{BL} / 6$ is shown in light gray while the apoE is shown in black.

FIGURE 1. Northern blot analysis of CD36 mRNA levels in different tissues.

at 6, 16, and 20 weeks of chow diet (Figure 2a). Indeed, CD36 overexpression was at least 100\% higher at 6 weeks and $30 \%$ higher at 20 weeks in $\mathrm{apoE}^{-/-}$compared to wildtype mice. It is to be noted that young apoE mice ( 0 weeks of diet, 4-week-old animals) did not show differences in CD36 transcription compared to wild type (Figure $2 \mathrm{~b}$ ). The hearts of both C57BL/6 and apoE deficient mice contained not only the usual CD36 mRNA, but also a lower abundant transcript of a lower molecular weight. This second observed transcript might arise from the use of an alternative polyadenylation site [29]. Results in mRNA levels were confirmed at the protein level by Western blots (Figure 3a). CD36 heart protein levels showed an increase of $100 \%$ at 3 and 6 weeks, and between $40 \%$ to $50 \%$ at 16 and 20 weeks in apoE $\mathrm{E}^{-/-}$mice, compared to wild type (Figure 3b).

\section{mRNA and protein levels of CD36 in the testis}

Northern blot shows that CD36 mRNA levels are upregulated, by at least $100 \%$ at 6,16 , and 20 weeks of chow diet, in testis of chow fed apoE $\mathrm{E}^{-/-}$, compared to wild type (Figures $4 \mathrm{a}$ and $4 \mathrm{~b}$ ). In contrast, no increase in CD36 mRNA levels were observed in wild-type mice (0- to 20-week chow fed diet). Moreover, no differences in CD36 transcription levels were present between 4-week-old apoE $\mathrm{E}^{-/-}$and wild-type mice ( 0 weeks of diet) (Figures $4 \mathrm{a}$ and $4 \mathrm{~b}$ ). The CD36 protein expression levels, in testis of deficient $\mathrm{apoE}^{-/-}$mice, was 

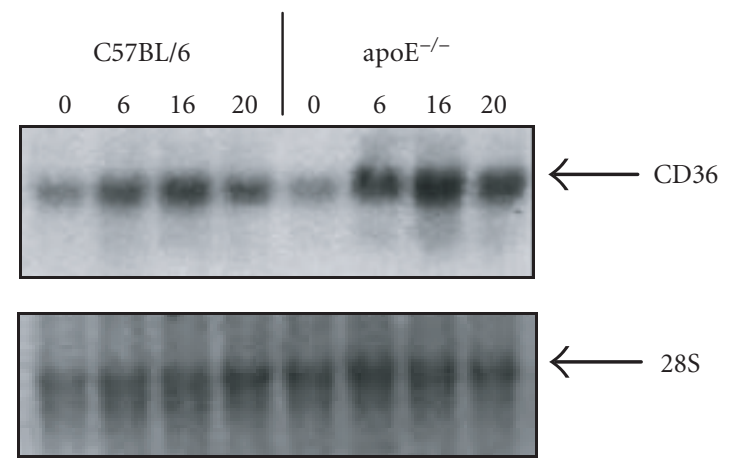

(a) Representative Northern blot showing CD36 mRNA expression in hearts of chow fed apoE $\mathrm{E}^{-/}$mice, in comparison to wild type (C57BL/6). Blots contained $20 \mu \mathrm{g}$ of total RNA. The $0,6,16$, and 20 correspond to the number of weeks of chow diet. The $28 \mathrm{~S}$ expression served as a control for loading and for quantification.

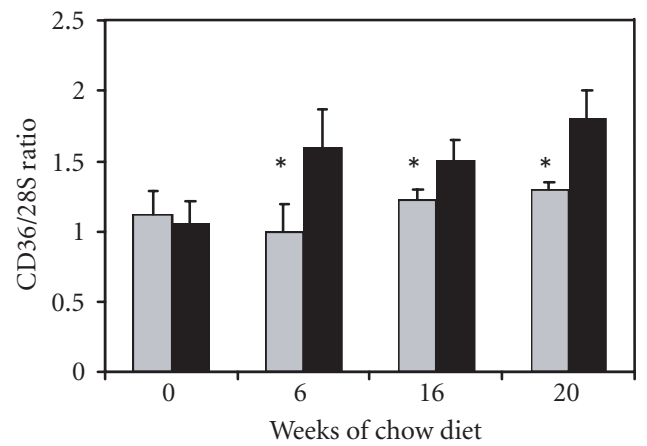

(b) Quantification of heart CD36 signals reported to $28 \mathrm{~S}$ levels. C57BL/6 is shown in light gray while the apoE is shown in black. ${ }^{*} P<.05$ compared to deficient apoE mice.

Figure 2. Northern blot analysis of CD36 mRNA levels in the heart.

significantly increased $(P<.05)$ at 16 weeks compared to the levels observed in wild-type mice (Figures $5 a$ and $5 b$ ).

\section{Immunohistochemistry}

An anti-CD36 polyclonal antibody stained heart endothelial cells lining arterioles and terminal capillaries (Figures $6 \mathrm{~b}$ and $6 \mathrm{~d}$ ). CD36 immunohistochemical distribution was similar, regardless of the duration of the diet, in the hearts of apoE $\mathrm{E}^{-/}$and wild-type mice. CD36 in testis was localized to spermatids and spermatozoids (Figures $6 \mathrm{f}, 6 \mathrm{~g}, 6 \mathrm{i}$, and $6 \mathrm{j}$ ) and to capillary endothelial cells (data not shown). A non-immune guinea pig serum, used as control, did not show any specific labeling (Figures 6a, 6c, 6e, and 6h).

\section{DISCUSSION}

This study reports, for the first time, a significant increase in CD36 mRNA and protein expression in the heart and testis of apoE ${ }^{-/-}$mice, compared to wild type (C57BL6). Several lines of evidence back the above statement: (1) Northern

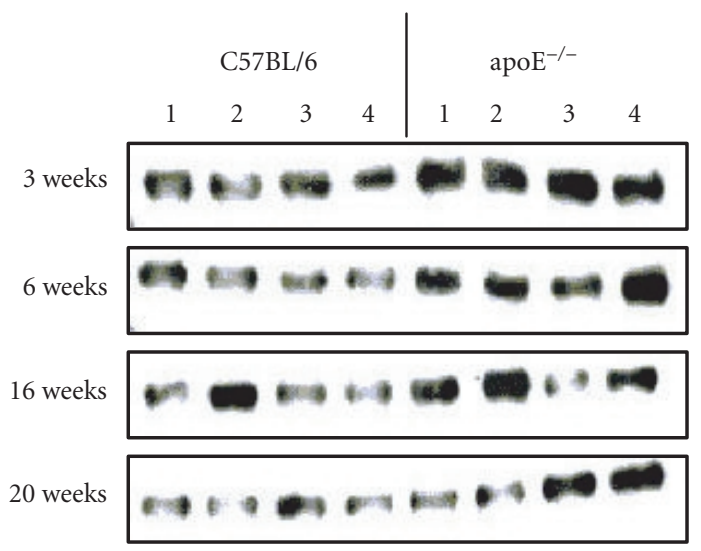

(a) Representative western blot of CD36 protein expression in hearts of chow fed apoE ${ }^{-/-}$mice, in comparison to wild type (C57BL/6). Blots contained $50 \mu \mathrm{g}$ of membrane proteins. The $0,6,16$, and 20 correspond to the number of weeks of chow diet. A control for loading and quantification was also used on the Coomassie gel (not shown).

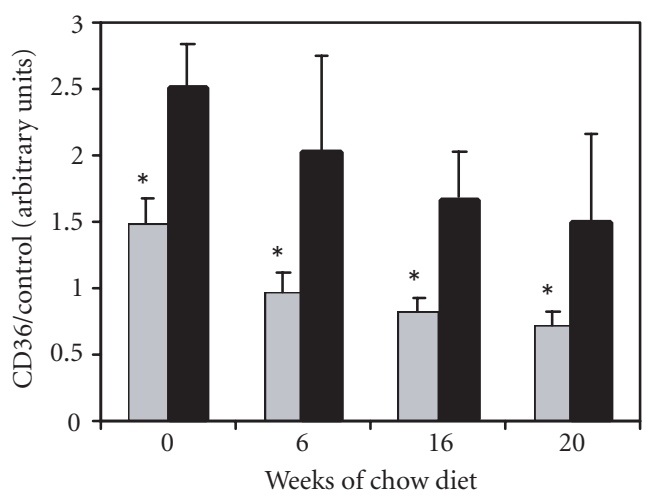

(b) Quantification of heart CD36 signals reported to a control protein. C57BL/6 is shown in light gray while apoE is shown in black. ${ }^{*} P<.05$ compared to deficient apoE mice.

FIgURE 3. Western blot analysis of CD36 protein levels in the heart.

blots of heart and testis showed CD36 mRNA levels to be significantly increased, at 6,16 , and 20 weeks in $\mathrm{apoE}^{-/-}$, compared to wild type. (2) Likewise, CD36 protein expression levels in hearts and testis was increased at 6,16, and 20 weeks in $\mathrm{apoE}^{-/-}$, compared to wild type. (3) Wild-type mice did not show, between 0 and 20 weeks of diet, changes in CD36 mRNA and protein expression levels in the heart or testis. (4) Finally, immunohistochemistry analysis showed CD36 to be localized on endothelial cells lining arterioles and terminal capillaries in the heart while it is localized in spermatids, spermatozoids, and capillary endothelial cells in the testis.

The present study has observed a significant upregulation of CD36 in cardiac cells, in apoE deficient animals compared to wild type. Such an increase in heart-CD36 expression could be related to cell lipid metabolism and to high cholesterol levels. Indeed, previous work performed on different mice models, (NOD, KKAy, and high fat diet Swiss 


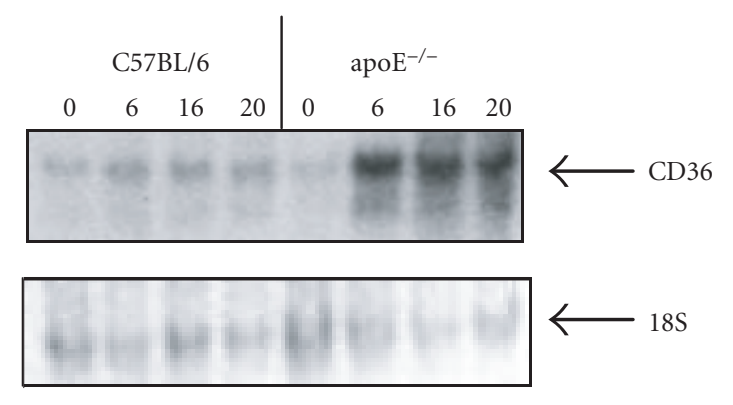

(a) Representative Northern blot showing CD36 mRNA levels in testis of chow fed apoE $\mathrm{E}^{-/-}$mice, in comparison to wild type (C57BL/6). Blots contained $20 \mu \mathrm{g}$ of total RNA. The $0,6,16$, and 20 correspond to the number of weeks of chow diet. The $18 \mathrm{~S}$ expression served as a control for loading and for quantification.

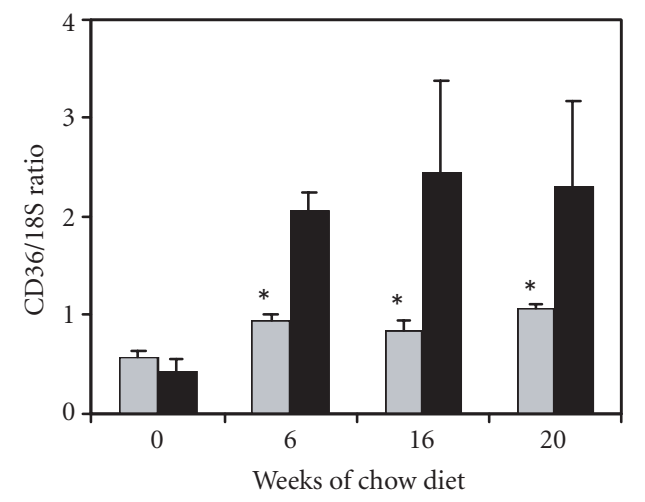

(b) Quantification of testis CD36 signals, reported to $18 \mathrm{~S}$ control levels. C57BL/6 is shown in light gray while apoE is shown in black. ${ }^{*} P<.05$ compared to apoE $\mathrm{E}^{-/-}$mice.

FIgURE 4. Northern blot analysis of CD36 mRNA levels in the testis.

Webster), show an upregulation of CD36 in the heart of these animals that are associated to high level of plasma triglyceride [6]. Moreover, FAT/CD36 overexpression in muscle tissues of transgenic animals enhances cellular fatty acids uptake and oxidation by contracting muscle and a reduction of plasma triglycerides [30]. It is of interest to note that cardiac tissue possesses a high capacity to oxidize large amounts of long-chain fatty acids (LCFA) [31]. Molecules, such as LCFA, represent a major heart energy substrate and their oxidation is deemed vital to allow maximal cardiac work. CD36, known as FAT in rat's heart muscles, has been shown to have a sequence homology to a bovine receptor implicated in the transport of myocardial LCFA [4, 32]. Recently, the role of cardiac tissue CD36 was beautifully investigated through the use of subjects showing an abnormality in CD36 expression (type I and II CD36 deficiency) and their capacity for myocardial LCFA uptake. The absence of cellular CD36 expression by platelets or monocytes, as observed in individuals with a type I CD36 deficiency, is also observed in myocardial capillary endothelial cells [33]. Several mutations

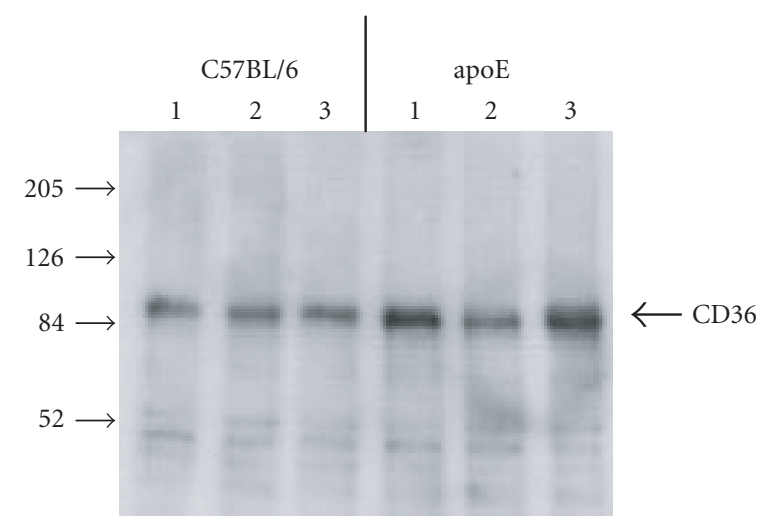

(a) Representative western blot showing CD36 protein expression levels in testis of chow fed apoE ${ }^{-/-}$mice at 16 week of diet, in comparison to wild type (C57BL/6). Blots contained $50 \mu \mathrm{g}$ of purified membrane proteins. Three testis samples of different apoE ${ }^{-/-}$and C57BL6 mice were used. A control for loading and for quantification was also used on the Coomassie gel (not shown).

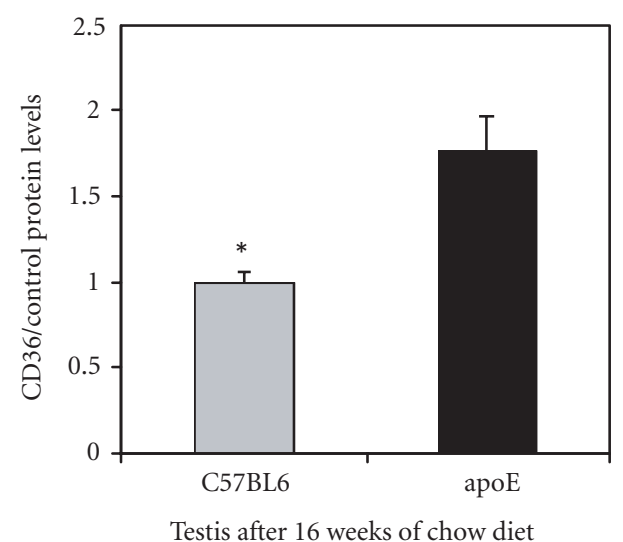

(b) Quantification of testis CD36 signals reported to a control protein. C57BL/6 is shown in light gray while the apoE is shown in black. ${ }^{*} P<.05$ compared to apoE ${ }^{-/-}$mice at 16 weeks of diet.

FIGURE 5. Western blot analysis of CD36 protein levels in the testis.

(deletion, insertion, and punctual mutation) in the CD36 gene have been identified in type I deficiency [34]. Myocardial capillary endothelial cells, in type I CD36-deficient individuals, show a lack of myocardial LCFA accumulation and metabolism in the myocardium $[33,34,35,36]$. Type I CD36-deficient individuals are reported to present cardiac troubles as hereditary hypertrophic cardiomyopathy. In contrast, in type II CD36 deficiency, where the absence of CD36 expression is only observed in platelets but not monocytes, the accumulation in the heart of LCFA analog (BMIPP or beta-methyl-p-iodophenyl pentadecanoic acid) is reduced but not totally absent, as in type I [33]. It is conceivable, that the up-regulation of $\mathrm{CD} 36$ in apoE ${ }^{-/-}$mice results from LCFA accumulation and/or enhanced blood viscosity due to increased cholesterol levels. Increase in heart-vascular 


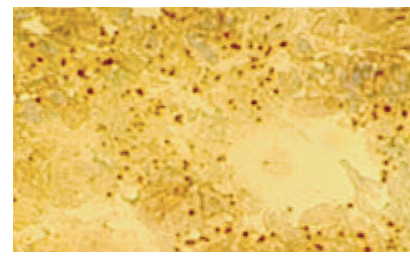

(a)

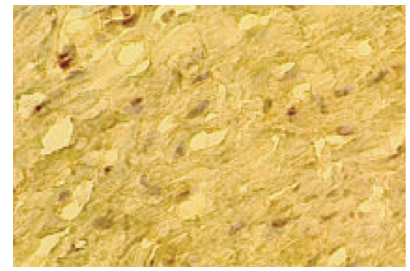

(c)

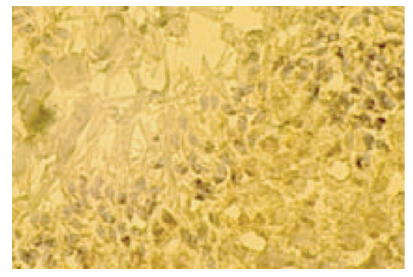

(e)

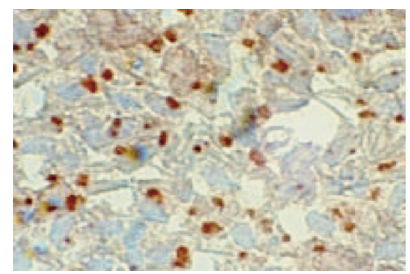

(g)

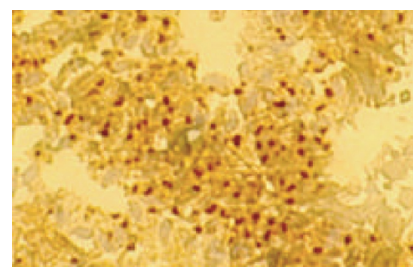

(i)

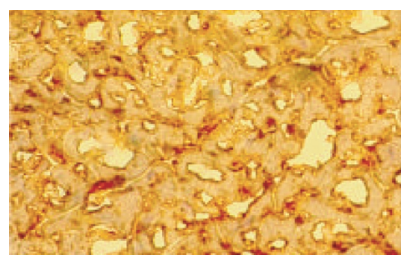

(b)

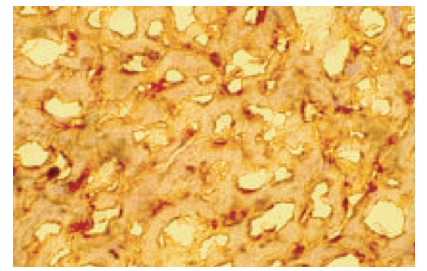

(d)

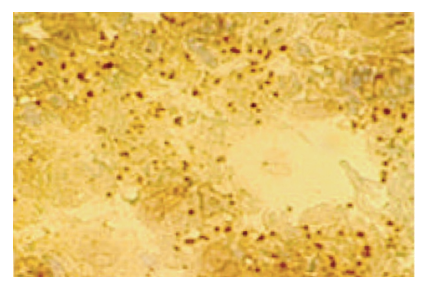

(f)

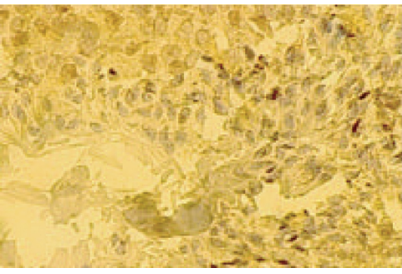

(h)

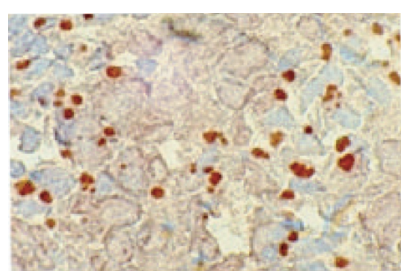

(j)
FIgURE 6. Immunohistochemistry analysis of CD36 in the heart and testis: CD36 immuno-staining of murine heart and testis at 16 weeks of chow diet. Heart ((b) and (d)), and testis ((f), (g), (i), and (j)) were immuno-stained through the use of a guinea pig anti-murine CD36 polyclonal antibody. Heart ((a) and (c)) and testis ((e) and (h)) negative controls were performed using a non-immune guinea pig serum. (a), (b), (e), (f), (g) show wild-type (C57BL/6) hearts or testis. Panels (c), (d), (h), (i), (j) show apoE ${ }^{-/-}$hearts or testis. Magnifications are X100 for (a), (b), (c), (e), (f), (h), (i), and X250 for $(\mathrm{g}),(\mathrm{j})$.
CD36 expression could allow the heart to better adapt to its environment.

Data presented in this study reports, for the first time, an enhanced CD36 mRNA and protein expression in the testis of apoE deficient mice in comparison to wild type. Abumrad et al showed the presence of FAT/CD36 in rat testis [4]. The localization and the function of FAT/CD36 in rat testis are at this stage unknown. Other scavenger receptors of the same class as CD36, SR-BI, and SR-BII have been found to be expressed in testis. In sertoli cells, SR-BI plays an important role in the phagocytosis of the apoptotic spermatogenic cells by recognizing phosphatidylserine exposed on the surface of these cells [37]. Moreover, SR-BI is expressed by another important cell in testis, Leydig cells, implicated in testosterone production [38]. Gonadotrophic hormone treatment of rats induces an increase in SR-BI expression by Leydig cells and a concomitant reduction in testosterone levels. Moreover, SRBI allows Leydig cells to make a selective uptake of cholesterol ester. Such an uptake of cholesterol ester may presumably allow a renewal of testosterone production. Expression of scavenger receptor SR-BII by Leydig cells remains negligible and unaffected by gonadotrophic hormone treatment [38]. On analysis of testis CD36 immuno-staining, we were surprised to identify CD36 expression at the head of the spermatids and spermatozoids, beside endothelial cell capillaries. The expression of CD36 in endothelial cell is not surprising and could be related to lipid metabolism. However, the role and function of CD36 in the spermatozoid is still at this stage unknown. High CD36 expression by spermatozoid could be related to the high level of cholesterol, present in the apoE deficient mice, and be implicated in the spermatogenesis process. Several studies indicate the importance of hypercholesterolaemia in the spermatogenesis and secretory functions of Leydig and Sertoli cells. Yamamoto et al has shown that hypercholesterolaemia could have a detrimental effect on Leydig and Sertoli cells secretory functions and the overall sperm fertilizing capacity [39]. Moreover, in apoE deficient mice fed with high cholesterol diet, Moghadasian et al has shown an arrest of spermatogenesis and the atrophy of seminiferous tubules [40]. The absence of an enzyme, the hormone-sensitive lipase (HSL), in an HSL knockout mouse induces a significant reduction of mature spermatids and a loss of mobility of spermatozoids [41]. It is interesting to note that HSL, an enzyme that catalyzes the hydrolysis of triacylglycerol, could play an important role in the regulation of CD36 expression $[42,43,44,45]$. Taken together, these results suggest a potential role of CD36 in spermatogenesis.

In conclusion, in this study we have shown that CD36 is significantly up-regulated in heart and testis of apoE deficient mice. The heart CD36 up-regulation is related to parenchymal cell lipid metabolism and in particular to LCFA uptake. Moreover, increase in CD36 expression in testis, spermatids and spermatozoids may potentially indicate a new, yet unknown role, for this scavenging receptor in the fertility mechanism. To elucidate and determine the function and the importance of CD36 in testis and in the spermatogenesis process, further investigations would be realized. 


\section{ACKNOWLEDGMENTS}

This work was supported by the French Ministry of Education and Scientific Research (grant MESR ACC-SV9) and by the European Network on Atherosclerosis (ENA, BIOMED 2, grant \# PL 1195). Eric Malaud was supported by a PhD fellowship awarded by "la Région Rhône-Alpes." We would like to warmly thank Prof Christopher Glass (Department of Cellular and Molecular Medicine, School of Medicine, University of California, San Diego, La Jolla, USA) for a generous gift of a guinea pig anti-CD36 polyclonal antibody.

\section{REFERENCES}

[1] Asch AS, Barnwell J, Silverstein RL, Nachman RL. Isolation of the thrombospondin membrane receptor. J Clin Invest. 1987;79:1054-1061.

[2] Endemann G, Stanton LW, Madden KS, Bryant CM, White RT, Protter AA. CD36 is a receptor for oxidized low density lipoprotein. J Biol Chem. 1993;268:221-236.

[3] Tandon NN, Lipsky RH, Burgess WH, Jamieson GA. Isolation and characterization of platelet glycoprotein IV (CD36). J Biol Chem. 1989;264:7570-7575.

[4] Abumrad NA, el Maghrabi MR, Amri EZ, Lopez E, Grimaldi PA. Cloning of a rat adipocyte membrane protein implicated in binding or transport of longchain fatty acids that is induced during preadipocyte differentiation. Homology with human CD36. J Biol Chem. 1993;268:17665-17668.

[5] Talle MA, Rao PE, Westberg E, et al. Patterns of antigenic expression on human monocytes as defined by monoclonal antibodies. Cell Immunol. 1983;78:83-99.

[6] Greenwalt DE, Scheck SH, Rhinehart-Jones T. Heart CD36 expression is increased in murine models of diabetes and in mice fed a high fat diet. J Clin Invest. 1995;96:1382-1388.

[7] Edelman P, Vinci G, Villeval JL, et al. A monoclonal antibody against an erythrocyte ontogenic antigen identifies fetal and adult erythroid progenitors. Blood. 1986;67:56-63.

[8] Greenwalt DE, Watt KW, So OY, Jiwani N. PAS IV, an integral membrane protein of mammary epithelial cells, is related to platelet and endothelial cell CD36 (GP IV). Biochemistry. 1990;29:7054-7059.

[9] Greenwalt DE, Mather IH. Characterization of an apically derived epithelial membrane glycoprotein from bovine milk, which is expressed in capillary endothelia in diverse tissues. J Cell Biol. 1985;100:397-408.

[10] Turner GD, Morrison H, Jones M, et al. An immunohistochemical study of the pathology of fatal malaria. Evidence for widespread endothelial activation and a potential role for intercellular adhesion molecule- 1 in cerebral sequestration. Am J Pathol. 1994;145:10571069.

[11] Knowles DM, Tolidjian B, Marboe C, D’Agati V, Grimes M, Chess L. Monoclonal anti-human monocyte antibodies OKM1 and OKM5 possess distinctive tissue dis- tributions including differential reactivity with vascular endothelium. J Immunol. 1984;132:2170-2173.

[12] Greenwalt DE, Lipsky RH, Ockenhouse CF, Ikeda $\mathrm{H}$, Tandon NN, Jamieson GA. Membrane glycoprotein CD36: a review of its roles in adherence, signal transduction, and transfusion medicine. Blood. 1992;80:1105-1115.

[13] Navazo MD, Daviet L, Savill J, Ren Y, Leung LL, McGregor JL. Identification of a domain (155-183) on CD36 implicated in the phagocytosis of apoptotic neutrophils. J Biol Chem. 1996;271:15381-15385.

[14] Oquendo P, Hundt E, Lawler J, Seed B. CD36 directly mediates cytoadherence of Plasmodium falciparum parasitized erythrocytes. Cell. 1989;58:95-101.

[15] Steinberg D, Parthasarathy S, Carew TE, Khoo JC, Witztum JL. Beyond cholesterol. Modifications of lowdensity lipoprotein that increase its atherogenicity. $N$ Engl J Med. 1989;320:915-924.

[16] Fogelman AM, Van Lenten BJ, Warden C, Haberland ME, Edwards PA, Macrophage lipoprotein receptors. J Cell Sci. 1988;9(Suppl):135-149.

[17] Nicholson AC, Frieda S, Pearce A, Silverstein RL, Oxidized LDL binds to CD36 on human monocyte-derived macrophages and transfected cell lines. Evidence implicating the lipid moiety of the lipoprotein as the binding site. Arterioscler Thromb Vasc Biol. 1995;15:269-275.

[18] Huh HY, Pearce SF, Yesner LM, Schindler JL, Silverstein RL. Regulated expression of CD36 during monocyteto-macrophage differentiation: potential role of CD36 in foam cell formation. Blood. 1996;87:2020-2028.

[19] Nakata A, Nakagawa Y, Nishida M, et al. CD36, a novel receptor for oxidized low-density lipoproteins, is highly expressed on lipid-laden macrophages in human atherosclerotic aorta. Arterioscler Thromb Vasc Biol. 1999; 19:1333-1339.

[20] Puente Navazo MD, Daviet L, Ninio E, McGregor JL. Identification on human CD36 of a domain (155-183) implicated in binding oxidized low-density lipoproteins (Ox-LDL). Arterioscler Thromb Vasc Biol. 1996;16:1033-1039.

[21] Nozaki S, Kashiwagi H, Yamashita S, et al. Reduced uptake of oxidized low density lipoproteins in monocyte-derived macrophages from CD36-deficient subjects. J Clin Invest. 1995;96:1859-1865.

[22] Febbraio M, Podrez EA, Smith JD, et al. Targeted disruption of the class $\mathrm{B}$ scavenger receptor CD36 protects against atherosclerotic lesion development in mice. $J$ Clin Invest. 2000;105:1049-1056.

[23] Febbraio M, Abumrad NA, Hajjar DP, et al. A null mutation in murine CD36 reveals an important role in fatty acid and lipoprotein metabolism. J Biol Chem. 1999;274:19055-19062.

[24] Tontonoz P, Nagy L, Alvarez JG, Thomazy VA, Evans RM. PPARgamma promotes monocyte/macrophage differentiation and uptake of oxidized LDL. Cell. 1998;93:241-252.

[25] Nagy L, Tontonoz P, Alvarez JG, Chen H, Evans RM. Oxidized LDL regulates macrophage gene expres- 
sion through ligand activation of PPARgamma. Cell. 1998;93:229-240.

[26] Chomczynski P, Sacchi N. Single-step method of RNA isolation by acid guanidinium thiocyanate-phenolchloroform extraction. Anal Biochem. 1987;162:156159.

[27] Sambrook J, Fritsch EF, Maniatis T. Molecular Cloning: A Laboratory Manual, 2nd ed., Cold Spring Harbor, New York, NY: Cold Spring Harbor Laboratory; 1989.

[28] Huang JT, Welch JS, Ricote M, et al. Interleukin4-dependent production of PPAR-gamma ligands in macrophages by 12/15-lipoxygenase. Nature. 1999;400:378-382.

[29] Wahle E, Keller W. The biochemistry of $3^{\prime}$-end cleavage and polyadenylation of messenger RNA precursors. Annu Rev Biochem. 1992;61:419-440.

[30] Ibrahimi A, Bonen A, Blinn WD, et al. Muscle-specific overexpression of FAT/CD36 enhances fatty acid oxidation by contracting muscle, reduces plasma triglycerides and fatty acids, and increases plasma glucose and insulin. J Biol Chem. 1999;274:26761-26766.

[31] Neely JR, Rovetto MJ, Oram JF. Myocardial utilization of carbohydrate and lipids. Prog Cardiovasc Dis. 1972;15:289-329.

[32] Tanaka T, Kawamura K. Isolation of myocardial membrane long-chain fatty acid-binding protein: homology with a rat membrane protein implicated in the binding or transport of long-chain fatty acids. J Mol Cell Cardiol. 1995;27:1613-1622.

[33] Watanabe K, Ohta Y, Toba K, et al. Myocardial CD36 expression and fatty acid accumulation in patients with type I and II CD36 deficiency. Ann Nucl Med. 1998;12:261-266.

[34] Nozaki S, Tanaka T, Yamashita S, et al. CD36 mediates long-chain fatty acid transport in human myocardium: complete myocardial accumulation defect of radiolabeled long-chain fatty acid analog in subjects with CD36 deficiency. Mol Cell Biochem. 1999;192:129_ 135.

[35] Watanabe K, Toba K, Ogawa Y, et al. Hypertrophic cardiomyopathy with type I CD36 deficiency. Jpn Circ J. 1998;62:541-542.

[36] Hwang EH, Taki J, Yasue S, et al. Absent myocardial iodine-123-BMIPP uptake and platelet/monocyte CD36 deficiency. J Nucl Med. 1998;39:1681-1684.

[37] Shiratsuchi A, Kawasaki Y, Ikemoto M, Arai H, Nakanishi Y. Role of class B scavenger receptor type I in phagocytosis of apoptotic rat spermatogenic cells by Sertoli cells. J Biol Chem. 1999;274:5901-5908.

[38] Reaven E, Zhan L, Nomoto A, Leers-Sucheta S, Azhar S. Expression and microvillar localization of scavenger receptor class B, type I (SR-BI) and selective cholesteryl ester uptake in Leydig cells from rat testis. J Lipid Res. 2000;41:343-356.

[39] Yamamoto Y, Shimamoto K, Sofikitis N, Miyagawa I. Effects of hypercholesterolaemia on Leydig and Sertoli cell secretory function and the overall sperm fertiliz- ing capacity in the rabbit. Hum Reprod. 1999;14:15161521.

[40] Moghadasian MH, Nguyen LB, Shefer S, McManus BM, Frohlich JJ. Histologic, hematologic, and biochemical characteristics of apo E-deficient mice: effects of dietary cholesterol and phytosterols. Lab Invest. 1999;79:355364.

[41] Osuga J, Ishibashi S, Oka T, et al. Targeted disruption of hormone-sensitive lipase results in male sterility and adipocyte hypertrophy, but not in obesity. Proc Natl Acad Sci USA. 2000;97:787-792.

[42] Yeaman SJ. Hormone-sensitive lipase-a multipurpose enzyme in lipid metabolism. Biochim Biophys Acta. 1990;1052:128-132.

[43] Holst LS, Hoffmann AM, Mulder H, et al. Localization of hormone-sensitive lipase to rat Sertoli cells and its expression in developing and degenerating testes. FEBS Lett. 1994;355:125-130.

[44] Holst LS, Langin D, Mulder H. Molecular cloning, genomic organization, and expression of a testicular isoform of hormone-sensitive lipase. Genomics. 1996;35:441-447.

[45] Kraemer FB, Patel S, Saedi MS, Sztalryd C. Detection of hormone-sensitive lipase in various tissues. I. Expression of an HSL/bacterial fusion protein and generation of anti-HSL antibodies. J Lipid Res. 1993;34:663-671.

* Corresponding author.

Current address: Thrombosis Research Institute (TRI), Emmanuel Kaye Building, Post-Genomics Atherothrombosis Laboratory, Manresa Road, London SW3 6LR, UK

E-mail: zibara@tri-london.ac.uk

Fax: +44 20 73518324; Tel: +44 2073518314 

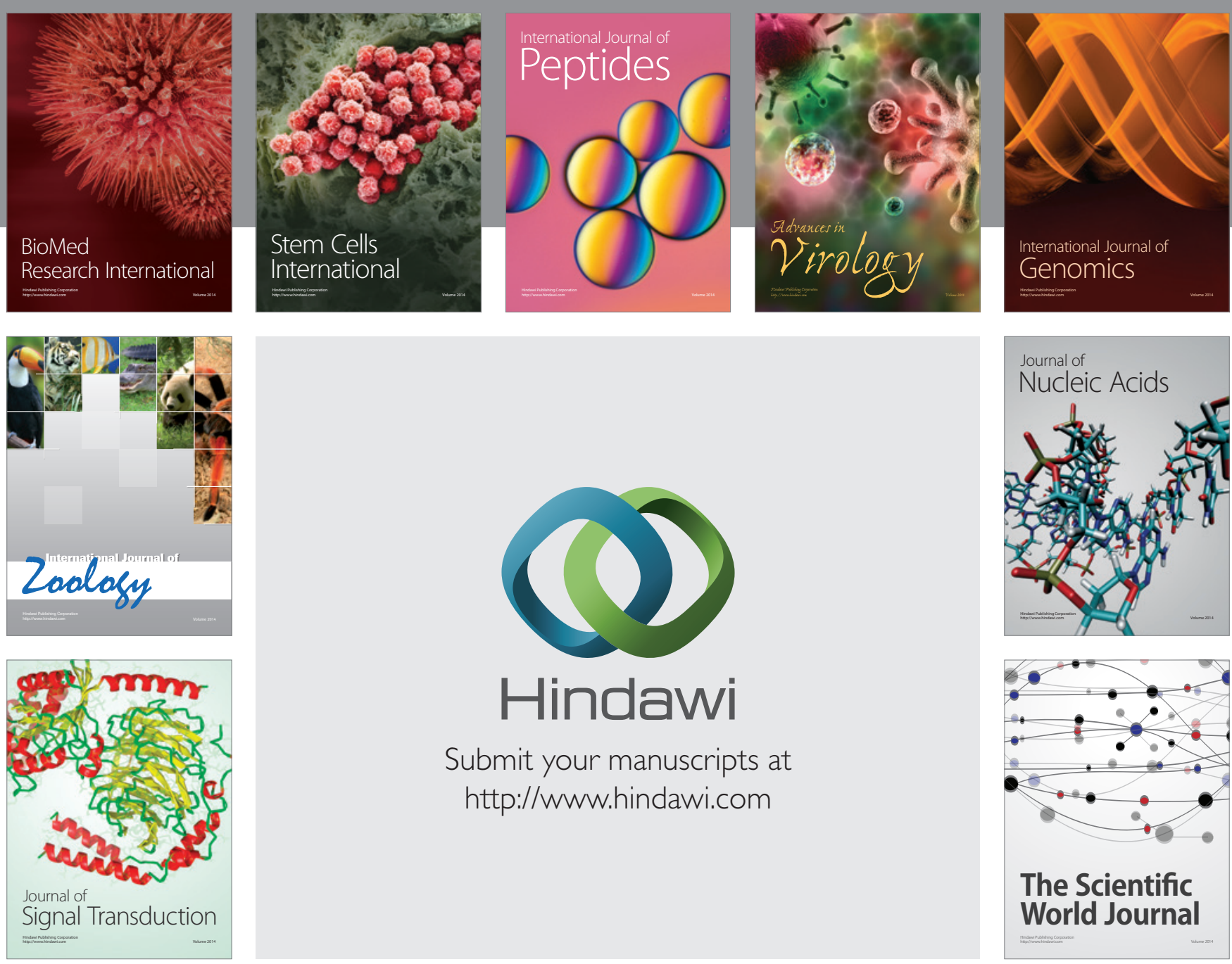

Submit your manuscripts at

http://www.hindawi.com
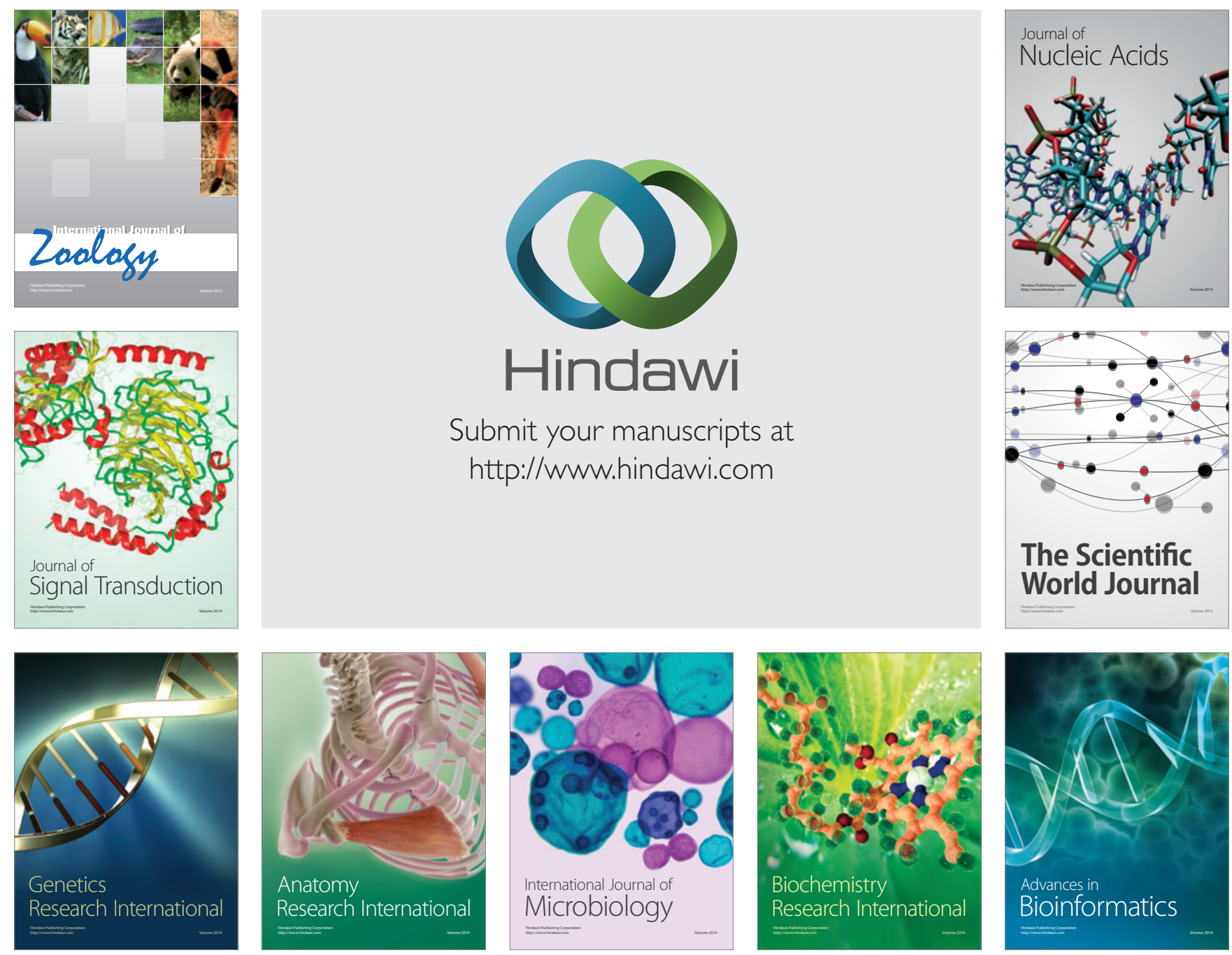

The Scientific World Journal
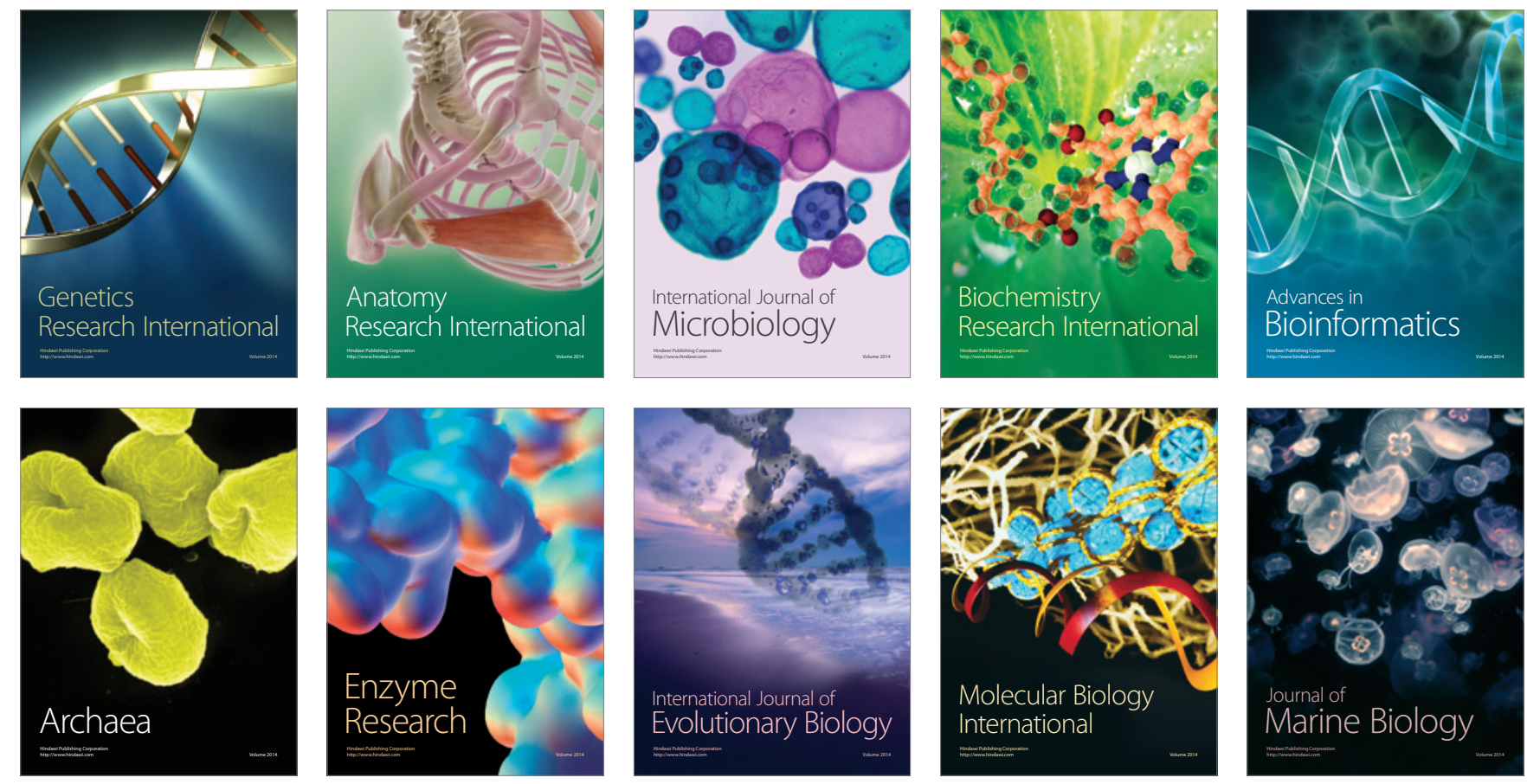